\title{
Development and validation of educational videos addressing indwelling catheterization
}

\author{
Marina B. Rossi ${ }^{1}$, Rui Carlos N. Baptista ${ }^{2}$, Rosali Isabel B. Ohl ${ }^{1}$, Tania A.M. Domingues ${ }^{1}$, Alba Lucia B.L. de Barros ${ }^{1}$, \\ Juliana de Lima Lopes*1 \\ ${ }^{1}$ Paulista Nursing School, Federal University of São Paulo, São Paulo, SP, Brazil \\ ${ }^{2}$ Coimbra College of Nursing, Coimbra, Portugal
}

Received: August 2, 2018

Accepted: November 18, $2018 \quad$ Online Published: November 26, 2018

DOI: $10.5430 /$ jnep.v9n3p109

URL: https://doi.org/10.5430/jnep.v9n3p109

\begin{abstract}
Objective: Developed and validate educational videos addressing the female and male indwelling catheterization techniques in adult patients.

Methods: Methodological study divided into two stages: development and validation of a script and the filming, editing and validation of videos. The script was written in the storyboard format, which was validated by eight nurse experts using the Delphi technique. The educational videos were filmed according to this validated script and were validated by 71 undergraduate nursing students using a five-point Likert scale.

Results: The final script was composed of eight items: concept, reasons, material, instructions, male and female indwelling catheterization, indwelling catheter care, and complications. Five rounds were needed for the script to be validated by experts, a process that lasted nine months. The scenes were filmed, edited and inserted in the animated texts. The final versions were watched by 71 first-year undergraduate nursing students from a public university located in São Paulo. The mean scores assigned by the students to the eight items were greater than four. The item that obtained the highest mean was "complications related to indwelling catheterization", with a mean score of 4.80. The item with the lowest score was "reasons" with a mean of 4.38 . Assessment of the set of items ("did you understand this video?") also obtained a mean score of 4.38. Agreement among students was also significant $(p<.001)$.

Conclusions: The script was developed and validated by experts, while the educational videos that resulted from this script were validated by first-year undergraduate nursing students.
\end{abstract}

Key Words: Urinary catheterization, Video recording, Education, Nursing

\section{INTRODUCTION}

Nursing is a dynamic profession that includes technical and managerial processes and employs several practical activities. Appropriate training influences these professionals' clinical practice and improve patient safety. ${ }^{[1]}$ For this reason, universities have increasingly sought to implement active methodologies and appealing teaching tools that facilitate retention of knowledge and autonomy of students. ${ }^{[2,3]}$ Active methodologies are student-centered approaches that enable students learn how to learn. The main aspect of such an approach is the active participation of students in the teaching process, including new and different practice settings. ${ }^{[4]}$

The pedagogical combination of both online and presen-

*Correspondence: Juliana de Lima Lopes; Email: julianalimalopes@ gmail.com; Address: Paulista Nursing School, Federal University of São Paulo, São Paulo, SP, Brazil. 
tial education methods through the use of a "blended learning" approach has been used to support individual students' needs. ${ }^{[5]}$ Blended learning refers to an educational approach that combines traditional classroom methods with online materials and activities. ${ }^{[6,7]}$ Videos are one of the online materials that can be used. The progressive use of technology in education suggests that video will become a popular teaching tool. As a resource to improve clinical skills, universities have also been successfully using videos to create a shared active learning experience amongst groups of nursing students in order to enhance their education. ${ }^{[8,9]}$ Video education has many advantages over traditional education, including efficiency, convenience, and individualized learning. An educational video is a versatile tool that can be used to support professors in the classroom, in simulation laboratories or at distance, using the internet and can expand access to knowledge. ${ }^{[4]}$

Among the various tools that can be used in teaching, educational videos stand out due to their capacity to illustrate complex phenomena that require extensive abilities of representation from professors and abstract reasoning abilities on the part of students. Videos also facilitate the demonstration of situations, the reproduction of which is very difficult. ${ }^{[10,11]}$ An educational video is a versatile tool that can be used to support professors in the classroom or in a simulation laboratory or, at a distance, through the internet ${ }^{[4]}$ or mobile devices $^{[12]}$ to expand access to knowledge. This tool is a practical method, with a good cost-benefit profile and the scenes can be watch multiple times, as many times as necessary ${ }^{[13-17]}$ and can help the students in acquiring new skills and their learning process. ${ }^{[11]}$ The three steps to develop a video are: pre-production, production and post-production. Pre-production is the development of a script and can be considered the filming strategies and population; production is the video recording, and can be considered the lighting and position of cameras and microphone; and post-production is the video editing and inclusion of audio. ${ }^{[18]}$ Another important step is validate the video by experts and the population who are supposed to use the video. ${ }^{[19]}$

Several studies have used this tool in education. Study shows that this tool contribute to nurse's training, improving the quality of care delivery. ${ }^{[10]}$ Bennett and Glover ${ }^{[20]}$ developed a study to evaluate nursing students' and lecturers' opinions on video usage in an undergraduate degree programme and the results showed that the professors felt that using video reduced the need to repeat lectures, and also allowed them to review and improve their teaching methods and the nursing students cited the convenience of online video access. Another study whose showed that exposing undergraduates to a short educational video was effective in increasing their short- term knowledge about fertility issues $(p<.001)$, infertility risk factors $(p<.001)$ and the definition of infertility $(p<$ $.001){ }^{[21]}$ A study whose objective was evaluate the learning retention of undergraduate medical students through the use of educational videos on orotracheal intubation, evaluated 30 undergraduate medical students that were randomized in two groups: one received educational videos and the other received theoretical material (checklist). The results showed that all students demonstrated improved practical and theoretical knowledge on orotracheal intubation procedure $(p<$ $.00)$ and, regarding theoretical knowledge, the study group that used videos had a higher performance in the evaluation $(p<.041) .^{[22]}$ Piliced et al. ${ }^{[23]}$ developed a study to compare the effectiveness of video education and traditional skill demonstration in teaching sterile surgical technique (SST) to first-year medical students, and to determine which method students preferred. The results showed that video education is superior to traditional skill demonstration in providing medical students with knowledge of SST $(p<.0001)$. Video education can increase medical students' knowledge before their operating room experience to ensure that a sterile environment is maintained for patients. ${ }^{[23]}$

A video can contribute to learning about invasive and complex procedures, because together with a simulation, it provides a controlled and appealing environment, minimizing stress and enabling students to experience a situation in advance, so students will be more confident and self-assured when a real event takes place. ${ }^{[13]}$ Indwelling urinary catheterization is the situation, among the various procedures and nursing techniques, that causes students to feel the most stressed. ${ }^{[24]}$ Therefore, this study's objective was to develop and validate educational videos addressing indwelling catheterization in both men and women.

\section{Methods}

The objective of this descriptive, methodological study was to present valid and reliable educational videos to be used in the teaching of undergraduate nursing students. This study was conducted from July 2014 to September 2015 in two stages, according to the steps described by other authors, ${ }^{[10,19]}$ as shown in Figure 1.

\subsection{First Phase: Development and validation of a script of videos addressing indwelling catheterization}

In this phase, a script that was composed of eight items (concept, reasons, material, instructions to patients, female and male catheterization, catheter care, and complications) was developed based on the literature and on the researchers' experience, resulting in two educational videos (male and female indwelling catheterization). The script was written in 
the storyboard format, which is a script with detailed instructions for the audio and visual steps. ${ }^{[10]}$ It is composed of two parallel columns. The right column contains the audio (characters' speech, environmental noise, background music) and the left column presents the visual element that corresponds to the audio, with instructions regarding shooting angles and focus. ${ }^{[18]}$ The two columns represent the same period of time of a given scene; that is, the visual part portrays what the viewer is supposed to see while listening to the text described in the right column. ${ }^{[18]}$

First phase: development and validation of educational videos addressing indwelling catheterization

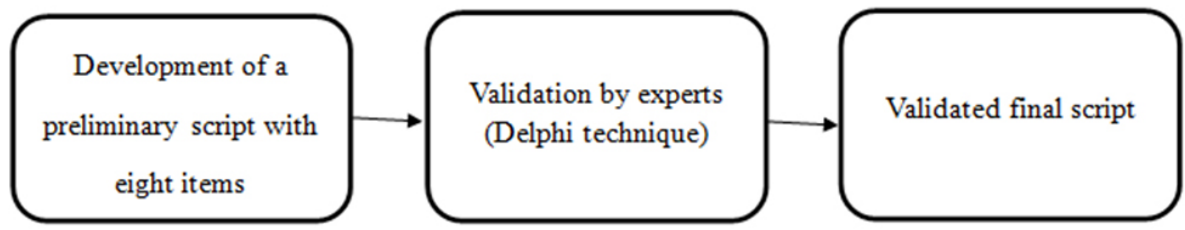

Second phase: filming, editing and validating the educational videos

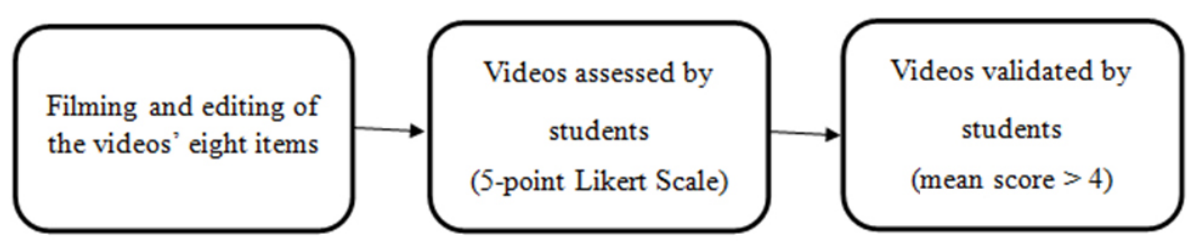

Figure 1. Scheme of the study's phases. São Paulo, SP, Brazil, 2016

This script was validated using the Delphi technique, which consists of repeatedly assessing an instrument, until consensus is reached among judges (experts on the topic). ${ }^{[25]} \mathrm{Com}-$ ments from one round are collected, analysed and integrated into the next round to collect opinions from these experts. The advantages of Delphi technique are: different opinions and consensus among experts; the anonymous of the process; this process can be carried out via email and does not require for the experts to physically meet. ${ }^{[26-28]}$ This technique has been used to validate instruments and video scripts. ${ }^{[29-31]}$ The script of the present study was reformulated after each round according to the experts' suggestions. Those parts for which consensus was not reached were reassessed in the subsequent rounds, until all judges reached $100 \%$ agreement regarding changes. The script was assessed using an instrument with a Likert scale employed in a previous study ${ }^{[19]}$ that addressed the following: sequence, content, clarity, and language. The score for each item ranges from 1 to 3 , in which $1=$ totally inadequate; 2 = partially adequate; and $3=$ totally adequate. If the nurse considered the script to be partially adequate or totally inadequate, s/he was asked to suggest pertinent changes. Eight nurse experts who have experience with indwelling catheters were invited to validate the script. Four were professors and taught this topic to undergraduate students, while the other four were clinical nurses who routinely perform catheterization in their practice, all of whom

Published by Sciedu Press had more than two years of experience in their fields. ${ }^{[19]}$ The Delphi Technique allows the number of experts to be directly determined by the phenomenon one intends to study, ranging from 7 to 12 experts. ${ }^{[32,33]}$

\subsection{Second Phase: Filming, editing, and validation of ed- ucational videos}

The filming was based on the script validated in the previous stage and conducted in the simulation center of a public university in São Paulo, Brazil. Low-fidelity manikins were used and the scenario was set with realistic materials and equipment. Two nursing technicians, two nurses, and one technology consultant participated in the video as actors. The videos were filmed and edited with the aid of an audiovisual technician. A new round of editing was needed for final adjustments and the inclusion of two phrases that were not mentioned by the experts but were necessary to adapt the videos. The edited videos were presented to the first-year undergraduate nursing students of a public university in São Paulo. Inclusion criteria were being 18 years old or older, having no prior experience with indwelling catheterization, and signing free and informed consent forms. First-year students were chosen because catheterization is a procedure addressed beginning in the second year of the undergraduate program in this university. This stage was conducted in two classes on consecutive days. 
Of the 98 registered students, 71 met the inclusion criteria and the sample's statistical power was $94.7 \%$, with a significance level of $5 \%$ and variance of 10.78 . The students assessed understanding of each of the eight items presented in the videos and each video as a whole, using an instrument with a 5-point Likert scale used in a previous study ${ }^{[12]}$ for which $1=\mathrm{I}$ did not understand anything and $5=\mathrm{I}$ understood it perfectly and have no doubts. For the items to be considered comprehensible and validated by students, each item, and the video as a whole, should score equal to or higher than 4 (I understood almost everything). In addition to the content, students were asked to assess the video for images and audio, the environment were it was filmed and the characters.

\subsection{Data analysis}

The Wilcoxon test, which enables assessing inter-evaluator reliability, was used to verify agreement among the students' answers, and $p$ values $<.05$ were considered statistically significant. This study was approved by the Institutional Review Board at the São Paulo Hospital (UNIFESP/EPM) under No. 521800/2014. Additionally, both the experts and undergraduate students signed free and informed consent forms. The professionals who acted in and narrated the video voluntarily signed an audio/video release agreement.

\section{RESUlts}

\subsection{First Phase: Development and validation of a video script addressing indwelling catheterization}

Eight experts validated the video script using the Delphi technique. The experts were female nurses aged between 29 and 58 years old; they were 43.1 years old on average. Considering the highest degree attained for each nurse at the time of data collection, four had a $\mathrm{PhD}$, one was a $\mathrm{PhD}$ candidate, one had a Master's degree, one was attending a Master's program, and one had a specialization in Cardiology Nursing. Experience in the field ranged from six to 33 years, with an average of 19 years. Five rounds were necessary to validate the video script addressing indwelling catheterization, a process that lasted nine months. The initial script was presented in the first round and the experts suggested changes in 50 phrases, as well as changes in the sequence of stages of both the female and male indwelling catheterization. The mean score obtained by each item in this first round is presented in Figure 2.

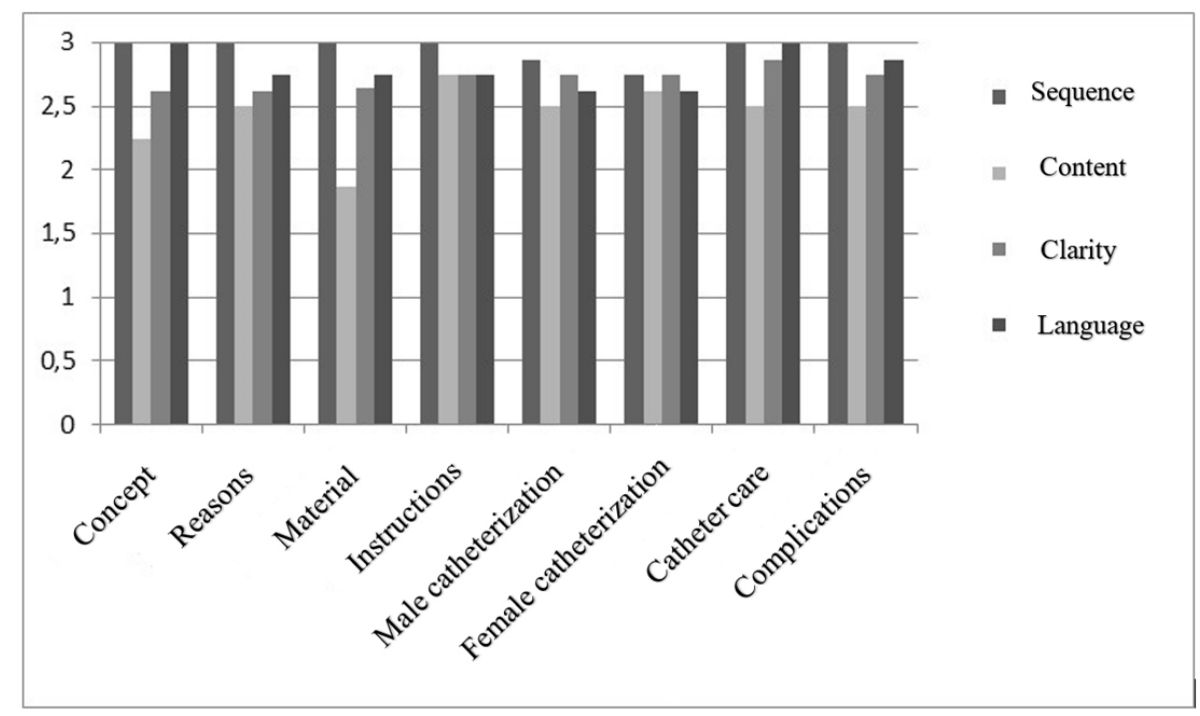

Figure 2. Mean scores assigned to the initial script in the first round. São Paulo, SP, Brazil, 2016

The phrases that did not score a 3 were reformulated based on the experts' suggestions and the new script was submitted to re-evaluation in the second round. A script addressing only the new sequence of male and female indwelling catheterization was also sent for assessment. In the second round, all the experts agreed with changes in the technical sequence of male and female indwelling catheterization, which was then considered validated. Additionally, in this round, changes were suggested in 13 of the script's phrases. The mean score obtained in each item are presented in Figure 3.

In the third round, the experts assigned a score of 3 to all phrases in the items: reasons for indicating indwelling catheterization; material; instructions provided to patients; male catheterization technique; female catheterization technique; and related complications. Therefore, these items were considered valid. The item "concept of indwelling catheterization" obtained a mean score of 2.87 for content and clarity and 3 for language. The topic "catheter care" 
obtained a mean score of 3 for content and clarity and a mean score of 2.87 for language. Only two phrases were reformulated according to suggestions, namely: "Indwelling urinary catheterization is an invasive procedure that consists of inserting a sterile catheter in the patient's bladder through the urethra to drain urine. According to resolution 450/2013 from COFEN, published on December 27th 2013, this pro- cedure is a responsibility of nurses" and "during every shift, look for: skin lesions; catheter exteriorization or obstruction; signs of infection such as fever, secretion through the urethra or along the catheter's length; and pain in the urethra." These phrases did not obtain consensus in the fourth round and were reformulated.

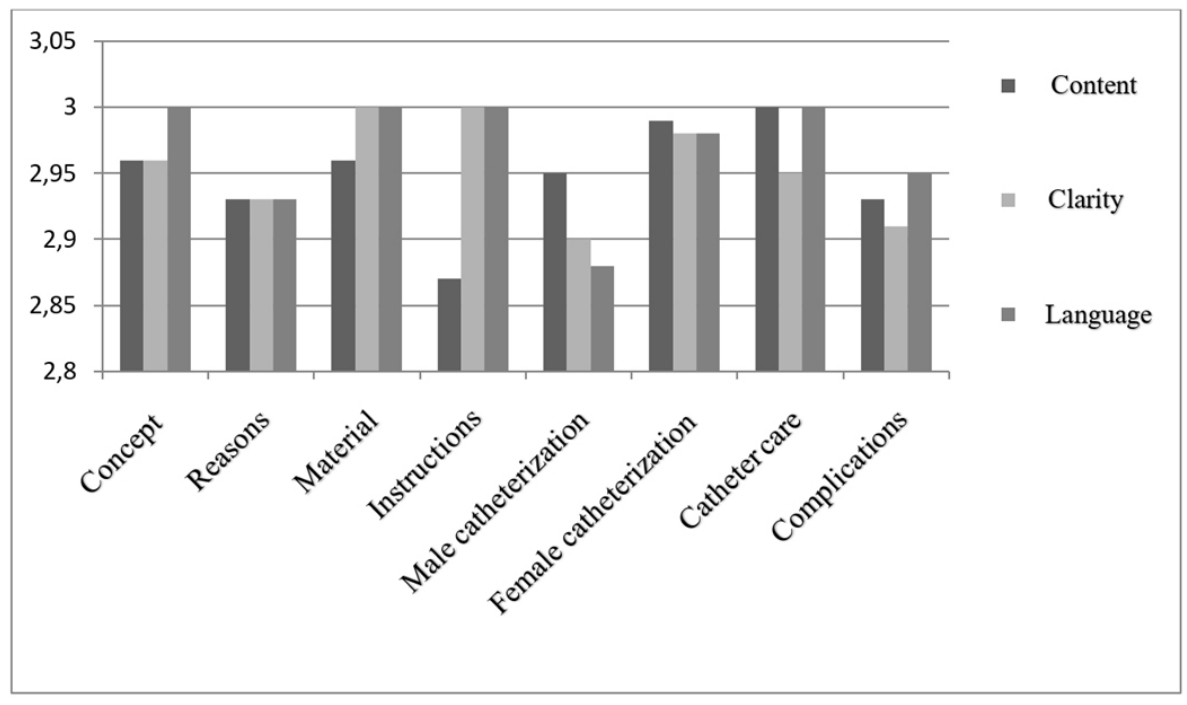

Figure 3. Mean scores assigned to the script in the second round. São Paulo, SP, Brazil, 2016

Consensus was obtained in the fifth round after assessing the phrases reformulated according to the suggestions provided in the previous round, so that the script of the educational videos addressing indwelling catheterization was considered valid. The items that more frequently generated disagreement among the judges were "concept of indwelling catheterization" and "catheter care", which required five rounds to obtain consensus, while the remaining items were validated in only three rounds. The experts suggested that other procedures be added to the catheter care item, such as verifying changes in the color of urine and signs of infections, as well as noting that each facility may employ different hygiene protocols.

\subsection{Second Phase: Filming, editing, and validation of ed- ucational videos}

In this phase, the eight items of the script were filmed and edited, which resulted in two educational videos. Nineteen hours of work with the audiovisual technician were necessary for the filming and editing steps. The scenes were edited and inserted in the animated texts. At the end of the first version, two phrases, not originally written in the original script nor mentioned by the experts in the previous stages were nonetheless deemed necessary and included, namely:
- Disinfecting the auxiliary table with alcohol at $70 \%$ before preparing the material and after using male and female indwelling catheters.

- Discarding the fields used in both male and female indwelling catheterization in the unit's hamper.

After the new version, the set of eight items totaled 37 minutes and 18 seconds. The duration of each item lasted between 24 seconds (concept) and 13 minutes and 14 seconds (male catheterization). The final versions were watched by 71 first-year undergraduate nursing students from a public university located in São Paulo. Of these, 64 were women aged 20.79 years old on average; ages ranged between 18 and 34 years old. Note that all items scored higher than 4 (see Table 1). No item was scored 1 (I did not understand anything). The item that obtained the highest mean was "complications related to indwelling catheterization", with a mean score of 4.80. The item with the lowest score was "reasons" (Did you understand in what situation(s) catheterization is indicated?) with a mean of 4.38. Assessment of the set of items ("did you understand this video?") also obtained a mean score of 4.38. Agreement among students was also significant $(p<$ .001) (see Table 1). These results confirm the validity of the educational videos. 
Table 1. Mean, median, standard deviation, minimum, maximum and $p$-value of the students' answers regarding each item and set of items. São Paulo, SP, Brazil, 2016

\begin{tabular}{|c|c|c|c|c|c|c|}
\hline & Mean & Median & SD $\ddagger$ & Min* & Max† & $p$-value \\
\hline Did you understand this video? & 4.38 & 4 & 0.54 & 3 & 5 & $<.001$ \\
\hline Did you understand the concept of an indwelling catheterization? & 4.56 & 5 & 0.6 & 2 & 5 & $<.001$ \\
\hline Did you understand in what situation(s) catheterization is indicated? & 4.38 & 5 & 0.85 & 2 & 5 & $<.001$ \\
\hline Did you understand what material is necessary for inserting a catheter? & 4.58 & 5 & 0.67 & 2 & 5 & $<.001$ \\
\hline Did you understand how to properly instruct a patient? & 4.7 & 5 & 0.62 & 2 & 5 & $<.001$ \\
\hline Did you understand male indwelling catheterization? & 4.65 & 5 & 0.56 & 3 & 5 & $<.001$ \\
\hline Did you understand female indwelling catheterization? & 4.66 & 5 & 0.51 & 3 & 5 & $<.001$ \\
\hline Did you understand how to properly care for an indwelling catheter? & 4.49 & 5 & 0.61 & 3 & 5 & $<.001$ \\
\hline Did you understand indwelling catheter-related complications? & 4.8 & 5 & 0.47 & 3 & 5 & $<.001$ \\
\hline MEAN SCORES & 4.58 & 4.67 & 0.35 & 3.44 & 5 & $<.001$ \\
\hline
\end{tabular}

Note. Mann-Whitney Test. $\mathrm{n}=71$. *Min = minimum. $†$ Max $=$ maximum. $\$$ SD $=$ Standard deviation.

\section{Discussion}

Most of the educational material found in the literature focuses on health education provided to patients and few papers address the development of educational videos directed to undergraduate students, while even fewer papers provide a detailed step-by-step explanation on how to develop and validate educational videos. ${ }^{[10,34-36]}$ Additionally, the development of educational videos has not been standardized. Recent papers describing the development of educational videos $^{[10,29,37]}$ implement the following stages, also employed in this study: pre-production (planning), production (filming), and post-production (editing). ${ }^{[18,38]}$ The development of a script is an essential step to organizing content and directing a video. ${ }^{[10]}$ The script used in this study was written according to the storyboard format, which is also used by other authors, ${ }^{[10,39]}$ because it portrays the structure of an educational video. We chose this format because it enables one to know exactly what the final video will be, as well as the filming process, avoiding the need for re-editing. ${ }^{[10,18]}$

The next step was validating the script. The choice of judges, or experts, to assess the script is supposed to take into account their experience with the topic, as established in the literature. ${ }^{[25]}$ In this study, we opted to choose both professors with experience in teaching students about indwelling catheterization and clinical nurses that insert catheters as part of their daily routines, because it is believed that the professional experience of experts with clinical practice as is as valid as an academic degree. Setting the number of experts at eight for the validation step was established based on other studies. ${ }^{[25,32,40]}$ Even though the Delphi technique is not commonly found in the literature to validate the scripts of educational videos, it was used in this study because it is widely used in the nursing field to develop and validate information through expert consensus. ${ }^{[25]}$
In regard to the number of rounds, one study reports that the Delphi technique generally requires two to three rounds to reach consensus among experts, though more rounds may be needed. ${ }^{[25]}$ This study required five rounds. We believe that this fact is related to the length of the video script, which is long due to a greater level of detail required by male and female indwelling catheterization, as well as the remaining items that compose it. Lack of communication among experts during the assessments, which is a step assumed in this technique, may hinder the clarification of potential divergences $^{[25]}$ and lead to the need for a greater number of rounds. In this study, we opted to establish $100 \%$ consensus among experts to validate the video script in a more rigorous way. According to the literature, consensus among experts is generally established between $70 \%$ and $80 \%$, depending on the objective and analysis of the answers. ${ }^{[25]}$

We carefully considered changes suggested by the experts to adapt content and the sequence of the script before implementing them. Literature addressing the theme admits variations in the indwelling catheterization technique and the Brazilian Federal Council of Nursing has not established strict steps for this procedure. Most of the experts' suggestions were accepted and the script was developed with the objective of presenting a technique that is anchored on the basic assumptions recommended for the correct insertion and maintenance of indwelling catheters, stressing that material and solutions may differ among facilities. The items "concept" and "catheter care" were the items that required a greater number of rounds for their validation. Changes were suggested for the item "concept", intended to clarify that within the nursing staff this procedure is a responsibility exclusive to nurses, but that within a multiprofessional team, physicians are also allowed to perform it. Four rounds were necessary for the phrasing to be considered appropriate by 
all experts. The concept of indwelling catheterization is key to understanding the procedure, its applications and who performs it; we believe the item received so many suggestions for this reason. Small changes were suggested in all rounds for the item "catheter care," such as replacing the word "secretion" with "exudate", including more appropriate terms, such as "microbiota", and attention was drawn to certain details, such as not allowing the collector bag to get stuck in the hospital bed rails, and clarifying what the signs of infection are. The professional experience of each expert in the face of various complications inherent to the procedure and to the maintenance of indwelling catheters was extremely important for the script to be complete and instructive. In regard to the script's content, the eight items that resulted in the videos were selected for students to acquire a broad perspective on the entire universe that permeates indwelling catheterization and not only the insertion technique. None of the experts suggested any item be included or excluded.

In the second phase of this study, filming, we opted to use manikins in a simulation laboratory to demonstrate male and female indwelling catheterization. The use of patient simulators enables safely demonstrating invasive techniques without invading the privacy of patients. ${ }^{[41]}$ Simulators also enable a scene to be repeated as many times as needed without harming or causing any discomfort to real patients. ${ }^{[10]}$ Three health workers (two nursing technicians and one nurse) and one technology consultant were invited to play actors in the video, in addition to the primary author, who played the role of the nurse and performed the main steps of the process. We believe that the fact that most actors were professionals who experience indwelling catheterization in their daily routines facilitated the demonstration of the technique and made it more believable. ${ }^{[10]}$ The narrator, also a nurse, used the correct length of time to narrate the content of each procedure because of her knowledge concerning the technique and material used. Studies that produce educational videos have also included health workers, ${ }^{[10,18,19,25,34,35]}$ because training lay actors to play the roles faithfully to reality would make the filming process more difficult. ${ }^{[10]}$ In order to give more veracity to the scene, the scenario chosen for filming the video reproduced a hospital room with characteristics similar to a real one. ${ }^{[10]}$

This study's objective was not to measure how effective the video was in the acquisition of knowledge on the part of students, but to measure how comprehensible it was. For this reason, first-year undergraduate students, who had no knowledge of the theme, were chosen to assess the video; the curriculum of the nursing undergraduate program at this university only addresses indwelling catheterization from the second year on. Therefore, we believe that the assessment performed by the first-year students revealed the video's clarity and comprehensiveness. Note that students who had had any previous contact with indwelling catheterization, whether because they had participated in extra-curricular activities, were already nursing technicians or aides, or had experienced the procedure themselves as patients, were excluded from the study. There is no consensus in the literature on what stages should be followed to assess an educational video. Some studies presenting the development of educational videos asked nurse experts to validate the video. $\left.{ }^{[10,37,42]}\right]$ In this study, we took into account that the educational video followed a script previously validated by experts, thus, its comprehensibility should be tested with its target audience.

The duration of an educational video is an important aspect to be discussed because it has to do with the attention span of viewers and difficulty in disseminating the material as in the case of making the videos available for download. ${ }^{[34]}$ One paper describing the steps for producing an educational video suggests that its duration should be between 10 and 20 minutes, ${ }^{[43]}$ while another study stresses it should not exceed 10 minutes. ${ }^{[10]}$ The duration of educational videos reported in the literature, however, ranges between two and 17 minutes. ${ }^{[10,34,35]}$ The set of eight items that resulted from this study lasted 37 minutes and 18 seconds, which exceeds the recommended amount of time. Nonetheless, when each item is separately analyzed, only two items (female and male indwelling catheterization) slightly exceed the 10 minutes recommended. Since the eight items can be watched with intervals and later will be used during clinical simulation with a manikin with predetermined pauses, we believe the duration will not be a problem that will affect the students' level of attention. This study's limitation is related to the video script's length. This is possibly why the assessment on the part of the experts was more difficult in the first rounds. Perhaps, the fact it was a long instrument led the experts, and also the researchers, to fail to perceive the need to include disinfection of the auxiliary table with alcohol at $70 \%$, as well as to address the discard of the fields in the unit's hamper, which required the video to be reedited at the end of the process.

\section{Conclusion}

The script of the educational videos addressing indwelling catheterization was developed and validated by experts, while the educational videos that resulted from this script were validated by first-year undergraduate nursing students. The development of educational videos addressing indwelling catheterization may encourage the development of videos addressing other nursing procedures, as well as contribute to meaningful learning and aid professors in their pedagogical 
practice.

\section{ACKNOWLEDGements}

This work was supported by National Council for Scientific and Technological Development - Cnpq (Grant number
454707/2014-2).

\section{Conflicts of InTERest Disclosure}

The authors declare that there is no conflict of interest.

\section{REFERENCES}

[1] Maloney S, Storr M, Paynter S, et al. Investigating the efficacy of practical skill teaching: a pilot-study comparing three educational methods. Advances in Health Sciences Education: Theory and Practice. 2013; 18(1): 71-80. PMid:22354336 https ://doi .org/10.1 007/s10459-012-9355-2

[2] Masson VA, Ribeiro RL, Hipólito MCV, et al. Construction of virtual learning objects for teaching the history of nursing. Revista Mineira de Enfermagem. 2014; 18(3): 764-769.

[3] Berbel NAN. Active methodologies and the nurturing of students' autonomy. Semina: Ciências Sociais e Humanas. 2011; 32(1): 25-40.

[4] Liemberguer JB. Active teaching-learning methodologies for pharmaceutical education: a report on experience. Interface (Botucatu). 2013; 17(47): 969-975.

[5] Coyne E, Rands H, Frommolt V, et al. Investigation of blended learning video resources to teach health students clinical skills: na integrative review. Nurse Educatiom Today. 2018; 63: 101-107. https://doi.org/10.1016/j.nedt.2018.01.021

[6] Garrison DR, Kanuka H. Blended learning: uncovering its transformative potential in higher education. The Internet and Higher Education. 2004; 7(2): 95-105. https://doi.org/10.1016/j. iheduc. 2004.02.001

[7] Park JY, Woo CH, Yoo JY. Effects of blended cardiopulmonary resuscitation and defibrillation e-learning on nursing students' selfefficacy, problem solving, and psychomotor skills. Computers, Informatics, Nursing. 2016; 34(6): 272-280. PMid:27046387 https : //doi.org/10.1097/CIN.0000000000000227

[8] Herrman J. Using film clips to enhance nursing education. Nurse Educator. 2006; 31(6): 264-269. https ://doi .org/10.1097/00 006223-200611000-00010

[9] Carpenter J, Stevenson B, Carson E. Creating a shared experience: using movies in nursing education. Nurse Educator. 2008; 33(3): 103104. PMid:18453923 https://doi.org/10.1097/01. NNE.000 0312182.98023 .86

[10] Ferreira MVF, Godoy S, Góes FSN, et al. Lights, camera and action in the implementation of central venous catheter dressing. Revista Latinoamericana de Enfermagem. 2015; 23(6): 1181-1186. PMid:26626011 https://doi.org/10.1590/0104-1169.0711 .2664

[11] Salina L, Ruffinengo C, Garrino L, et al. Effectiveness of an educational video as an instrument to refresh and reinforce the learning of a nursing technique: a randomized controlled trial. Perspectives on Medical Education. 2012; 1(2): 67-75. PMid:23316461 https://doi.org/10.1007/s40037-012-0013-4

[12] Hansen M, Oosthuizen G, Windsor J, et al. Enhancement of medical interns' levels of clinical skills competence and self-confidence levels via video iPods: pilot randomized controlled trial. Journal of Medical Internet Research. 2011; 13(1): e29.

[13] Arruda FT, Danek A, Abrão KC, et al. Preparation of educational videos for skills training for medical students in medical school. Revista Brasileira de Educação Médica. 2012; 36(3): 431-435.
[14] Allen WA, Smith AR. Effects of vídeo podcasting on psychomotor and cognitive performance, atitudes and study physical therapists. Innovations in Education and Teaching International. 2012; 49(4): 401-414. https://doi .org/10.1080/14703297.2012.728876

[15] Kay RH. Exploring the use of vídeo podcasts in education: a comprehensive review of the literarture. Computers in Human Behaviour. 2012; 28(3): 820-831. https://doi.org/10.1016/j.chb. 2012 .01 .011

[16] Hsin W, Cigas J. Short videos improve student learning in online education. Journal of Computing Sciences in Colleges. 2013; 28(5): 253-259.

[17] Schmid RF, Bernard RM, Borokhovski E, et al. The effects of technology use in postsecondary education: a meta-analysis of classroom applications. Computers \& Education. 2014; 72: 271-291. https://doi.org/10.1016/j. compedu . 2013.11.002

[18] Fleming SE, Reynolds J, Wallace B. Lights...Camera....Action! A guide for creating a DVD/vídeo. Nurse Educator. 2009; 34(3): 118 121. PMid:19412052 https://doi.org/10.1097/NNE.0b013e $3181 \mathrm{a} 0270 \mathrm{e}$

[19] Lopes JL, Nogueira-Martins LA, Barbosa DA, et al. Development and validation of an informative booklet on bed bath. Acta Paulista de Enfermagem. 2013; 26(6): 554-560.

[20] Bennett PN, Glover P. Video streaming: implementation and evaluation in an undergraduate nursing program. Nurse Education Today. 2008; 28(92): 253-258. PMid:17548131

[21] Conceição C, Pedro J, Martins MV. Effectiveness of a vídeo intervention on fertility knowledge among university students: a randomised pre-test/ post-test study. The European Journal of Contraception and Reproductive Health Care. 2017; 22(2): 107-113. PMid:28256912 https://doi.org/10.1080/13625187.2017.1288903

[22] Danek A, Arruda FT, Quilici AP. Comparing the Efficiency of Training in Orotracheal Intubation with Educational Video Versus Checklist. Revista Brasileira de Educação Médica. 2016; 40(4): 560-564.

[23] Pilieci SN, Salim SY, Heffernan DS, et al. A Randomized Controlled Trial of Video Education versus Skill Demonstration: Which Is More Effective in Teaching Sterile Surgical Technique? Surgical Infections Case Reports. 2018; 19(3): 303-312. PMid:29406814 https://doi.org/10.1089/sur.2017.231

[24] Evangelista RA, Hortense P, Sousa FAEF. Magnitude estimation of stress in view of nursing care. Revista Latinoamericana de Enfermagem. 2004; 12(6): 913-917. PMid:15678218

[25] Scarparo AF, Laus AM, Azevedo ALCS, et al. Reflections on the use of Delphi Technique in Research in Nursing. Revista da Rede de Enfermagem do Nordeste. 2012; 13(1): 242-251.

[26] Day J, Bobeva M. A generic toolkit for the successful management of delphi studies. Electronic Journal of Business Research Methods. 2005; 3(2): 103-116.

[27] Diamond IR, Grant RC, Feldman BM, et al. Defining consensus: a systematic review recommends methodologic criteria for reporting of Delphi studies. Journal of Clinical Epidemiology. 2014; 67(4): 401- 
409. PMid:24581294 https://doi.org/10.1016/j.jclinepi .2013 .12 .002

[28] Gracht HAVD. Consensus measurement in Delphi studies Review and implications for future quality assurance. Technological Forecasting \& Social Change. 2012; 79 (8): 1525-1536. https : //doi . org/10.1016/j.techfore.2012.04.013

[29] Barbosa RM, Bezerra AK. Validation of an educational video for the promotion of attachment between seropositive HIV mother and her child. Revista Brasileira de Enfermagem. 2011; 64(2): 328-334. PMid:21755218

[30] Lima MB, Rebouças CBA, Castro RCMB, et al. Construction and validation of educational video for the guidance of parentes of children regarding clean intermitente catheterization. Revista da Escola de Enfermagem da USP. 2017; 51: e03273.

[31] Mar P, Spears R, Reeb J, et al. Creation of a Collaborative Disaster Preparedness Video for Daycare Providers: Use of the Delphi Model for the Creation of a Comprehensive Disaster Preparedness Video for Daycare Providers. Disaster Medicine and Public Health Preparedness. 2018; 1-5.

[32] Reda E, Peniche ACG. Entry-instrument used in the patient's evaluation in a post-anaesthetic recovery room - a matter of great concern: care continuity. Acta Paulista de Enfermagem. 2008; 21(1): 24-31. https://doi.org/10.1590/S0103-21002008000100004

[33] Cunha ALSM, Peniche ACG. Content validity of an instrument to document recovery of patients in post anestesia care unit. Acta Paulista de Enfermagem. 2007; 20(2): 151-160.

[34] Sowan AK. Multimedia applications in nursing curriculum: The process of producing streaming videos for medication administration skills. International Journal of Medical Informatics. 2014; 83(7): 529535. PMid:24840676 https://doi.org/10.1016/j.ijmedinf .2014 .04 .004

[35] McConville SA, Lane AM. Using on-line video clips to enhance self-efficacy toward dealing with difficult situations among nurs- ing students. Nurse Education Today. 2006; 26(3): 200-208. PMid:16300862 https://doi.org/10.1016/j.nedt.2005.09 .024

[36] Cannon G, Kelly M, Lyng C, et al. The production and deployment of an on-line video learning bank in a skills training environment. AISHE-J: The all Ireland Journal of Teaching and Learning in Higher Education. 2009; 1(1): 3.1-3.11.

[37] Braga FTMM, Garbin LM, Marmol MT, et al. Oral Hygiene in Chemotherapy patients: construction and validation of an educational video. Revista de Enfermagem UFPE On Line. 2014; 8(10): 3331-3339.

[38] Corbally MA. Considering video production? Lessons learned from the production of a blood pressure measurement video. Nurse Education in Practice. 2005; 5(6): 375-379. PMid:19040848 https: //doi.org/10.1016/j.nepr.2005.04.003

[39] Razera APR, Buetto LS, Lenza NFB, et al. Video educational: teaching-learning strategy for patients chemotherapy treatment. Ciência, Cuidado \& Saúde. 2014; 13(1): 173-178.

[40] Cunha ALSM, Peniche ACG. Content validity of an instrument to document recovery of patients in post anesthesia care unit. Acta Paulista de Enfermagem. 2007; 20(2): 151-160.

[41] Teixeira CRS, Kusumota L, Pereira MCA, et al. Anxiety and performance of nursing students in regard to assessment via clinical simulations in the classroom versus filmed assessments. Investigación y Educación en Enfermeria. 2014; 32(2): 270-279.

[42] Garcia CIRS, Araújo T. Self-care modeling videos for spinal cord inhuries: design and production of a prototype. Revista de Enfermagem Referência. 2016; IV(8): 93-101.

[43] Williams NH, Wolgin F, Hodge CS. Creating an educational videotape. Journal for Nurses in Professional Developement. 1998; 14(6): 261-265. 